\title{
Retrograde amnesia: Role of temperature, dose, and duration of amnesic agent
}

ARTHUR CHERKIN, Psychobiology Research Laboratory, Veterans Administration Hospital. Sepulveda, Calif. 91.34.3, and Division of Anesthesia, University of California Medical Center. Los Angeles, Calif. 90024

In retrograde amnesia experiments, raising the temperature of etherization increases the ammesic effect by increasing the concentration (partial pressure) of the inspired ether vapor, rather than by an effect on body temperature. Thus, the enhanced effect of warm ether is another example of the dose-dependence of retrograde amnesia.

Among the controversial techniques of memory research is the use of ether anesthesia to induce retrograde amnesia. Heated ether, but not cold ether, causes amnesia (Jarvik, 1964; Alpern \& Kimble, 1967). Recurrent ambiguity concerning the significance of the temperature of etherization suggests a need for clarification.

The ambiguity arises from a confusion of the effect of elevated ether temperature with the effects of elevated body temperature. For example, a recent report (Alpern \& Kimble, 1967 ) of retrograde amnesia produced by heated liquid ether is introduced by citations of ether vapor effects in hyperthermic Ss, a quite different experimental situation. Similarly, in a review discussion (Halstead, Rucker; \& McMahon, 1967) of the influence of altered body temperature upon memory processes, it was deduced from ether studies in mice and rats (Jarvik, 1964; Herz, Peeke, \& Wyers, 1966; Pearlman, 1966) that: "Raising the temperature seems to prolong and potentiate the disruptive effect of ether." The context implies that memory disruption by ether was potentiated by raising the body temperature of the Ss. In the two experiments (Jarvik, 1964; Herz, Peeke, \& Wyers, 1966) that stated the temperature conditions, it was the temperature of the ether jar, containing liquid ether as well as the animals, that was raised. There is no reason to believe that exposure of mice or rats to $27-38 \mathrm{deg} \mathrm{C}$, for 15 to $70 \mathrm{sec}$, would raise their body temperatures above the normal values of $37.0-37.5$ deg C. The more likely interpretation is that heating the liquid ether simply increased the partial pressure (concentration) of ether in the vapor phase. Consequently, the "temperaturedependence" of retrograde amnesia reduces to dosedependence.

Dose-dependence has been demonstrated for several other amnesic agents, including carbon dioxide (Quinton, 1966), flurothyl (1), pentylenetetrazole (Weissman, 1967), and electroconvulsive shock (Jarvik \& Kopp, 1967; Miller, 1968). The inconsistent amnesic effects of ether (Jarvik, 1964; Herz, Peeke, \& Wyers, 1966; McGaugh, 1966; Pearlman, 1966; Alpern \& Kimble, 1967; Weissman, 1967; Wimer, 1968) suggest that the state of anesthesia per se does not cause retrograde amnesia. Rather, some unknown interaction between ether and neural mechanisms is responsible and this interaction is dose-dependent.

The interaction is also duration-dependent, as has been demonstrated with ether (Herz, Peeke, \& Wyers, 1966), carbon dioxide (Quinton, 1966; Paolino, Quartermain, \& Miller, 1968), flurothyl (1), and electroconvulsive shock (McGaugh, 1966; Jarvik \& Kopp, 1967). Dose and duration of inhaled compounds are interrelated because of uptake, distribution, and output factors (Papper \& Kitz, 1963). For a given exposure period, the effective partial pressure (or concentration) at the site of action is reached more rapidly, and persists longer, as the inspired partial pressure is increased. Thus, heating liquid ether, which raises the inspired partial pressure, not only increases the maximum partial pressure reached in the brain, but also prolongs the duration of the "amnesic partial pressure." Heated ether is more effective than room-temperature ether because the animal experiences both an increased dose and increased duration of the amnesic treatment.

Heated ether introduces a third variable, namely, hypoxia. Typical ether jar temperatures employed (Jarvik, 1964; Herz, Peeke, \& Wyers, 1966; Alpern \& Kimble, 1967) and the calculated equilibrium partial pressures (and ether vapor concentrations) are: $27 \mathrm{deg} \mathrm{C}, 581 \mathrm{~mm} \mathrm{Hg} \quad(77 \% \mathrm{v} / \mathrm{v})$; $31 \mathrm{deg} \mathrm{C}, 673 \mathrm{~mm} \mathrm{Hg}(89 \% \mathrm{v} / \mathrm{v})$; and $38 \mathrm{deg} \mathrm{C}, 867 \mathrm{~mm} \mathrm{Hg}$ $(>100 \% \mathrm{v} / \mathrm{v})$. The corresponding partial pressures (and concentrations) of oxygen in equilibrium mixtures of heated ether and air would be $38 \mathrm{~mm} \mathrm{Hg}(5.0 \% \mathrm{v} / \mathrm{v}), 18 \mathrm{~mm} \mathrm{Hg}(2.4 \%$ $\mathrm{v} / \mathrm{v})$, and $0 \mathrm{~mm} \mathrm{Hg}(0 \% \mathrm{v} / \mathrm{v})$, respectively. Although memory consolidation is said to be unaffected by hypoxia (Jarvik, 1964; Taber \& Banuazizi, 1966), the interaction between hypoxia and anesthesia introduces a potential variable.

The need to control dose, duration, and oxygen level makes the classical ether jar a questionable device for quantitative studies of retrograde amnesia. The internal temperature is variable, because of the disturbing effects of evaporative cooling, and of periodic ether replenishment and animal replacement. Ether vapor and oxygen concentrations fluctuate with repeated openings of the jar. The high partial pressure of saturated ether vapor necessitates short exposure times, to prevent excessive mortality. [The partial pressure at $31 \mathrm{deg} C$ is $673 \mathrm{~mm} \mathrm{Hg}(89 \% \mathrm{v} / \mathrm{v})$, or 11 times the lethal partial pressure (Raventos, 1956); only the limited exposure, of less than 2 min, prevents a $100 \%$ mortality rate. Even so, a mortality rate of $25 \%$ has been reported (Herz, Peeke, \& Wyers, 1966), raising the question of residual brain damage in the survivors.] All these methodological problems can be avoided by employing well-defined gaseous mixtures of ether-or preferably of a less flammable compound, like halothane-with air or oxygen, provided by clinical anesthesia machines or by simple laboratory apparatus, to eliminate "saturated" vapor conditions.

The importance of precise control over etherization conditions is further exemplified by a recent report (Wimer, 1968) that ether facilitated, rather than impaired, performance in a memory experiment. Such a possibility had been suggested (Cherkin, 1968) based on the argument that low doses of anesthetic agents have stimulatory effects and stimulant drugs facilitate memory processing. It is to be expected that ether would exert upon memory processes either no effect (McGaugh, 1966), a stimulating effect (Wimer, 1968), or a depressant effect (Jarvik, 1964; Herz, Peeke, \& Wyers, 1966; Pearlman, 1966; Alpern \& Kimble, 1967), depending upon the dose and duration of the ether treatment. The conclusion is inescapable that "anesthesia" per se is an inadequate and misleading criterion for retrograde amnesic effects.

A similar situation exists with retrograde amnesic treatments using convulsant drugs (Alpern \& Kimble, 1967; Weissman, 1967). Under conditions of flurothyl $\left(\mathrm{CF}_{3} \mathrm{CH}_{2} \mathrm{OCH}_{2} \mathrm{CF}_{3}\right)$ treatment (1) that caused rapid, full tonic extension in $100 \%$ of our Ss (two-day old cockerels, convulsed 64 min after a single learning trial) the proportion showing retrograde amnesia increased from $33 \%$ to $93 \%$, as the 
exposure to $1.7 \%$ flurothyl vapor increased from $2 \mathrm{~min}$ to $9 \mathrm{~min}$. We have demonstrated also that at a fixed duration of exposure, the retrograde amnesic effect is dependent upon the inspired concentration of flurothyl. With a fixed dose and fixed duration, the amnesic effect depends upon the interval between the learning trial and the flurothyl treatment, as predicted by consolidation theory. Our data confirm a growing body of evidence (McGaugh, 1966; Jarvik \& Kopp, 1967; Miller, 1968) that full tonic extension is an inadequate criterion for full retrograde amnesia.

The results of memory consolidation research will continue to be ambiguous and controversial until experimental methodology takes into strict account the role of dosedependence and duration-dependence of amnesic treatments. Optimal amnesic treatments require careful attention to the critical parameters of dose (ECS current; anesthetic vapor partial pressure): duration; oxygen partial pressure; and mortality rate. Inadequate dose or duration causes incomplete interruption of memory consolidation and leads to results that are interpretable as rapid consolidation. Excessive dose or duration causes a high mortality rate, that implies possible brain damage in the survivors. The confounding variables introduced by nonoptimal amnesic methodology provide a plausible, parsimonious interpretation of conflicting interpretations of retrograde amnesia experiments.

\section{REFERENCES}

ALPERN, H. P., \& KIMBLE, D. P. Retrograde annesic effects of diethyl ether and bis(trifluorocthyl) ether. Journal of Comparative \& Physiological P'sy chology, 1967,63, 168-171.

CHERKIN. A. Molecules, anesthesia, and menory. In A. Rich and N. Davidson (Eds.). Structural chemistry and molecular biology. San Francisco and London: W. H. Freeman and Co., 1968. Pp. 325-342.
HALSTEAD, W. C., RUCKER, W. B., \& McMAHON, J. P. Memory. Annual Review of Medicine, 1967, 18, 1-14.

HERZ, M. J., PEEKE, H. V. S., \& WYERS, E. J. Amnesic effects of ether and electroconvulsive shock in mice. Psychonomic Science, 1966, 4, 375-376.

JARVIK, M. E. The influence of drugs on memory. In H. Steinberg, A. V. S. de Reuck, \& J. Knight (Eds.), Animal behavior and drug action. Boston: Little-Brown, 1964. Pp. 44-61.

JARVIK, M. E., \& KOPP, R. Transcorneal electroconvulsive shock and retrograde amnesia in mice. Journal of Comparative \& Physiological Psychology, 1967, 64, 431-433.

McGAUGH, J. L. Time-dependent processes in memory storage. Science, $1966,153,1351-1358$.

MILLER, A. J. Variations in retrograde amnesia with parameters of electroconvulsive shock and time of testing. Journal of Comparative \& Phy siological Psychology, 1968, 66, 40-47.

PAOLINO, R. M. QUARTERMAIN, D., \& MILlER, N. E. Different temporal gradients of retrograde amnesia produced by carbon dioxide anesthesia and electroconvulsive shock. Journal of Comparative \& Physiological Psychology, 1966, 62, 270-274.

PAPPER, E. M., \& KITZ, R. J. (Eds.), Uptake and distribution of anesthetic agents. New York: McGraw-Hill, 1963.

PEARLMAN, C. A., JR. Similar retrograde amnesic effects of ether and spreading cortical depression. Journal of Comparative \& Physiological Psychology, 1966, 61, 306-308.

QUINTON, E. E. Retrograde amnesia induced by carbon dioxide inhalation. Psychonomic Science, 1966, 5, 417-418.

RAVENTÓS, J. The action of fluothane-a new volatile anaesthetic. British Journal of Pharmacology, 1956, 11, 394-397.

TABER, R. I., \& BANUAZIZI, A. $\mathrm{CO}_{2}$-induced retrograde amnesia in a one-trial learning situation. Psychopharmacologia (Berl.) 1966, 9, 382-391.

WEISSMAN, A. Drugs and retrograde amnesia. International Review of Neurobiology, 1967, 10, 167-198.

WIMER, R. E. Bases of a facilitative effect upon retention resulting from posttrial etherization. Journal of Comparative \& Physiological Psychology, 1968, 65, 340-342. NOTE

1. In experiments to be published. I am indebted to Miss Mayme Bailey and Mrs. Mary Garman for carrying out these experiments. 